DOI: $\underline{10.17805 / g g z .2019 .4 .3}$

\title{
Локальные и региональные контексты органного донорства: этика и эпистемология тела как дара*
}

\author{
С. Ю. Шевченко \\ Институт философии РАН; \\ Российский национальный исследовательский медицинский университет \\ имени Н. И. Пирогова, г. Москва
}

В статье рассматривается моральная риторика восприятия мертвого / умирающего тела как дара, использование которого возможно благодаря практикам органного донорства. Данная риторика сформировалась в странах, в которых действует правовая норма презумпциии несогласия на проведение эксплантации органов и, соответственно, работают opt-in программы донорства. Несмотря на то, что в России действует презумпция несогласия, периодически предлагается воспроизводить риторику тела как дара в русскоязычном региональном коммуникативном поле.

В статье представлена критика такого воспроизведения. В рамках ее осуществления вводится понятие этической и эпистемической инфраструктуры. Под такой инфраструктурой нами понимаются формы обоснования убеждений и действий субъектов, которые позволяют осуществляться конкретным правовым режимам и практикам. В рамках данной статьи, такими практиками выступают программы органного донорства. Функционирование инфраструктуры, обеспечивающей восприятие тела как дара, предполагает обязательное приписывание конкретного изелеполагания решению о возможности посмертного донорства. Эта логика подвергается критическому рассмотрению в оптике теории речевых актов Дж. Остина и теории рациональности Дю. Серля. Кроме того, проанализировань парадоксальные следствия такой логики для этических оснований паллиативной помощии.

Предложень более простые этические и эпистемические основания осуществления программ донорства, не требующих выраженного согласия потенцииального донора (opt-оит программы). Представляется достаточным, чтобы решение о донорстве органов было намеренным и обдуманным, но не обязательно «целенаправленньм».

\footnotetext{
* Статья подготовлена при финансовой поддержке РНФ в рамках проекта № 17-18-01444. The article was prepared with financial support from the Russian Science Foundation as part of the project No. 17-18-01444.
} 
Ключевые слова: донорство органов; биоэтика; тело как дар; эпистемическая инфраструктура; рациональность

\title{
Local and Regional Contexts of Organ Donation: Ethics and Epistemology of the Body as a Gift
}

\author{
S. Yu. Shevchenko \\ Institute of Philosophy, Russian Academy of Sciences; \\ Pirogov Russian National Research Medical University, Moscow
}

The article discusses the moral rhetoric of perceiving a dead / dying body as a gift that can be used in a framework of organ donation. This rhetoric has developed in countries that have legal provision for the presumption of non-consent to conduct organ explantations and, consequently, have opt-in donation programs. Despite the presumption of disagreement (and opt-out type of the donation program) in Russia, it is periodically proposed to reproduce this rhetoric in the Russian-speaking regional communicative field.

The article presents criticism of such a reproduction. As part of it, the concept of ethical and epistemic infrastructure is introduced. Such infrastructures are forms of substantiation of subjects' beliefs and actions that 'make things possible', allow specific legal regimes and practices to be implemented. In this article, organ donation programs are considered as such practices. The functioning of infrastructure ensuring perception of the body as a gift implies an obligatory attribution of specific goal-setting to a decision on the possibility of postmortem organ donation. This logic is subjected to a critical consideration from the viewpoints of $J$. Austin's speech act theory and J. Searle's theory of rationality. In addition, the paradoxical consequences of such logic for the ethical foundations of end-of-life care are analyzed.

We propose simpler ethical and epistemic grounds for implementing donor programs that do not require the expressed consent of a potential donor (opt-out programs). It seems sufficient that a decision on organ donation was intentional and deliberate, but not necessarily 'purposeful'.

Keywords: organ donation; bioethics; body as a gift; epistemic infrastructure; rationality

ВВЕДЕНИЕ.

ЭТИЧЕСКИЕ И ЭПИСТЕМИЧЕСКИЕ ИНФРАСТРУКТУРЫ OРТ-IN ПРОГРАММ ДОНОРСТВА

В странах, в которых действует презумпция несогласия на донорство органов, расширяется использование нарративных практик для привлечения внимания к проблемам трансплантологической помощи. В результате в рам- 
ках коммуникативных полей (существующих онлайн и офлайн) возникают локальные «информационные пузыри», в рамках которых возникают особые риторические, этические и эпистемические режимы. Например, на сайте австралийских администраторов программы донорства органов и тканей (Organ and Tissue Authority) действует раздел «Книга жизни», в котором публикуются истории семей доноров и реципиентов (Donation stories, s.d.: Электронный ресурс). Деятельность таких ресурсов направлена не только на медийную поддержку программ органного донорства, но и на формирование этических и эпистемических условий восприятия мертвого / умирающего тела как дара.

Такое восприятие собственного тела отнюдь не кажется универсально присущим современной западной культуре, не является оно и закономерным следствием эволюции некоторого модерного отношения к собственному телу (и биологическому организму). Скорее, формирование такого ракурса восприятия мертвого / умирающего тела является частью эпистемической и этической инфраструктуры opt-in программ донорства — т. е. таких программ, в которых требуется согласие потенциального донора на эксплантацию органов ${ }^{1}$. Под такой инфраструктурой нами понимаются формы обоснования убеждений и действий субъектов, которые позволяют осуществляться конкретным правовым режимам и практикам. В рамках данной статьи такими практиками выступают программы органного донорства, как требующие, так и не требующие выраженного согласия потенциального донора на участие в них.

В соответствии с этим можно предположить, что при сопоставлении различных региональных правовых режимов регулирования органного донорства уместно сравнивать не только саму по себе эффективность систем оказания трансплантологической помощи, но и этические и эпистемические условия и последствия функционирования этих систем.

Систематические обзоры ожидаемо показывают, что режимы с презумпцией согласия (opt-out) позволяют аккумулировать более существенные ресурсы донорских органов. Методы статистической экстраполяции позволяют предположить, что переход c opt-in на opt-out систему способен повысить число пересадок с использованием органов умершего донора на 38-83 \% в течение 11-13 лет. Для США, где действует презумпция согласия, а про-

\footnotetext{
${ }^{1}$ Понятие эпистемической инфраструктуры развито американской социальной исследовательницей Мишель Мерфи. Она описывает эпистемические инфраструктуры через совокупность практик количественной оценки и целенаправленного вмешательства, составляющих масштабные механизмы государственного, корпоративного и иных видов управления. Эта инфраструктура, по Мерфи, позволяет процессам производства и обмена знаний воплощаться в материальные объекты и практики - здания, дороги, бюрократические аппараты и т. д. (Murphy, 2017: 6).
} 
граммы в поддержку согласия на посмертное донорство обладают колоссальным медийным ресурсом, такой переход означал бы увеличение числа трансплантаций в диапазоне от 4,7 тыс. до 17,2 тыс. в год (Ahmad et al., 2019).

Значительное число авторов, представляющих страны, где действуют opt-in программы, согласны с мнением о большей эффективности opt-out программ. Однако они не видят возможностей перехода к правовому режиму презумпции согласия в связи с тем, что для этого отсутствуют этические и эпистемические условия. Т. е. признание автономии потенциального донора и невозможность наложить на него / нее обязательства задумываться о благе других людей видятся основными контекстами развития трансплантологических практик. В рамках этого не ставящегося под сомнение этического, эпистемического и политического контекста складываются региональные правовые режимы презумпции несогласия. С одной стороны, эти режимы отражают не только ценность автономии и отсутствие обязательного знания о потребности в донорских органах. С другой, они функционируют именно благодаря локальным коммуникативным феноменам вроде «Книги жизни», которые складываются в региональную этическую и эпистемическую инфраструктуру, создающую условия возможности opt-in программ через восприятие тела как дара. Эта инфраструктура предполагает осуществление, как минимум, двух функций. Эпистемическая функция заключается в представлении потребности в донорских органах не в виде статистических показателей (в «интерфейсе» которых осуществляется контроль и управление программами донорства), а в формате множественного и бесконечного нарратива о спасенных жизнях и «пожертвованных органах». Этическая, она же биополитическая, функция предполагает формирование особого взгляда на тело как на ресурс, относительно использования которого может быть принято определенное решение. Предполагается, что топос использования делает проблему посмертной судьбы тела очевидной, конкретной, операциональной и обращенной в публичное пространство.

Реализация данных функций предполагает изменение артикулируемых в публичном пространстве и усваиваемых отдельными индивидами образов смерти и умирания. Во-первых, смерть становится публичным и политическим процессом. Во-вторых, становится юридически не обязательным, но морально желательным всеобщее знание о том, что смерть является точкой возникновения общественно-полезных ресурсов (донорских органов). Втретьих, воля пациента относительно посмертной судьбы тела становится частью его личности и может быть включена в контекст пациентоориентированной заботы. 
Первые две черты, в целом, могут быть истолкованы как варианты реализации биополитики, управляющей населением, и утилитаристского этического бэкграунда этого управления. Третья же особенность выпукло очерчивает работу этической и эпистемической инфраструктуры, благоприятствующей восприятию и «функционированию» тела как дара. Детально эта инфраструктура и соответствующая ей точка зрения на пациенто-ориентированную паллиативную помощь детально артикулирована в недавно опубликованной в «Американском журнале трансплантологии» статье хирурга Кристофера Мичетти (Michetti, 2019). Он отрицает существование конфликта между благом для паллиативных пациентов и проведением терапии, направленной не на улучшение качества их жизни, а на сохранность их органов для последующего проведения трансплантации. Мичетти считает, что в случае получения согласия на эксплантацию органов, их сохранность входит в интересы пациента, поэтому вмешательства, сохраняющие кондиционность отдельных частей организма пациента, являются неотъемлемой частью пациентоориентированной паллиативной помощи. Эти заключения носят не только этический, но эпистемический характер: пациент, согласный на посмертное донорство, считается производящим дар, поэтому знание (предположение) о возможном будущем использовании его органов конституирует пациентское понимание блага, на которое обязаны ориентироваться медицинские работники. Такое понимание является необходимым компонентом этики и эпистемологии тела как дара. Природу этой необходимости мы попытаемся раскрыть в следующем разделе, рассматривая акт дарения в перспективе аналитической философии языка.

\section{ТРИ СПОСОБА «ЗАВЕЩАТЬ» ОРГАН}

Итак, формула «тело как дар» становится актуальной, когда посмертная судьба тела определяется открытым изъявлением воли дарителя. Нельзя быть дарителем по умолчанию, значит, эта формула применима только к ситуациям испрошенного согласия на посмертную эксплантацию органов. При этом согласие на эксплантацию органов по аналогии с дарением рассматривается как выбор, заслуживающий наивысшей моральной оценки, но при этом этически необязательный для всех и добровольный. Учитывая это, метафора дара может служить действенным инструментом социального подталкивания к выбору оптимальному для общества в целом, и при этом не несущему никаких рисков для выбирающего субъекта.

Однако моральное поощрение посмертного донорства - только одна сторона этического смысла формулы «тело как дар». Второй его стороной является распределение ответственности между всеми участниками процесса дарения. Начальной точкой этого процесса может служить высказанное ре- 
шение подарить нечто кому-то (сам акт дарения), а его завершением можно считать получение дара одаряемым или получения доступа к его использованию. Представим, что некто направляет в дар детскому дому несколько ящиков фруктов, считая, что растительные волокна и витамины благотворно скажутся на здоровье воспитанников. Из-за сбоя на почте ящики не попадают в детский дом или попадают позже максимального срока доставки. Фрукты испорчены, дар не осуществлен. В таком случае почта несет ответственность перед дарителем. Даже если даритель умрет во время доставки, он сохраняет этическую субъектность благодаря высказанной при жизни воле. Сотрудники почты, из-за которых не был осуществлен дар, могут быть подвергнуты моральному порицанию. Если же фрукты испортятся в самом детском доме, потому что его воспитанники стали лучше питаться и не хотят есть фрукты, то дар все равно осуществлен, хотя и не использован. По аналогии можно судить и о распределении ответственности в случае согласия на посмертное донорство органов. Человек, открыто и добровольно согласившийся на него, дарит свои органы нуждающимся в пересадке. Если такие нуждающиеся действительно есть, то ответственность за то, что они получат донорские органы в надлежащем состоянии, должна лечь на систему трансплантологической помощи. Более того, орган должен быть пересажен тому пациенту, у которого результаты пересадки будут наилучшими среди всех нуждающихся в этой операции. Вероятно, такое приписывание ответственности искажает этическую суть трансплантологии: невозможно нести моральную ответственность за каждый не пересаженный орган. Медицинская этика может предусматривать ответственность за неиспользованные возможности, однако само пространство возможностей при этом должно быть гораздо более ограниченным. Вместе с тем колоссальный груз ответственности логически вытекает из приравнивания согласия на посмертное донорство к дарению. Формула «тело как дар» не только налагает неадекватные моральные обязательства на участников системы трансплантологической помощи, но и, как мы покажем ниже, искаженно очерчивает этическую конфигурацию самой ситуации согласия на посмертное донорство. Если акт выбора о посмертной судьбе тела не может пониматься как дар в полном этическом смысле этого слова, то и распределение ответственности, налагаемой этим выбором, должно быть иным.

Понятия, которыми мы пользуемся при описании человеческих действий, во многом определяют ответственность, которую мы налагаем на человека, совершившего действия. Воспользуемся примером, который предложил более полувека назад один из крупнейших философов языка Джон Остин (Austin, 1966). Допустим, ученик пролил чернила на уроке. Чтобы определить меру его ответственности, учитель может задать ему три разных вопроса: «Ты сделал это намеренно?», «Ты сделал это умышленно?» или «Ты 
сделал это нарочно?». Ответ на первый вопрос должен характеризовать ментальное состояние ученика в момент действия (например, «Я не хотел проливать чернила»). Ответ на второй — характеризует процесс размышления, предшествовавший действию (например, «Я сделал это, не подумав», при этом желание пошалить само по себе не отрицается). Ответ на третий вопрос характеризует цель действия, ситуацию которая должна возникнуть после действия (например, «Я рассчитывал, что чернила впитаются в лист промокательной бумаги»). Итак, по Остину, действие имеет три возможных характеристики: намерение (intention); обдуманность или взвешенность (deliberaration, consideration); целенаправленность (purposefulness). При этом каждая из трех характеристик или несколько сразу могут быть приписаны или не приписаны действию, т. е. оно может быть ненамеренным, необдуманным или нецеленаправленным.

Дарение, акт направления кому-то подарка, обычно обладает всеми тремя описанными выше чертами. Как правило, дарение - это действие намеренное (я хочу подарить), взвешенное (я подумал, что и как подарить) и целенаправленное (я представляю себе ситуацию, которая последует за приемом подарка, и считаю ее желательной). Попробуем исключить ту или иную характеристику из акта дарения, чтобы подобрать ту конфигурацию действия, которая лучше всего описывает акт согласия на посмертное донорство.

Если мы исключаем намерение из триады характеристик, описывающих дарение, получается нечто похожее на откуп. Человек не имеет желания совершать действие, но совершает его в результате размышлений и ради определенной цели. Так, к примеру, богатые граждане Франции откупались от службы в наполеоновской армии; у них не было субъективного намерения отдавать кому-то свои деньги, но они делали это, взвесив все «за» и «против», ради того, чтобы не подвергать свою жизнь риску.

При исключении взвешенности, но сохранении целенаправленности и намеренности дара получается нечто схожее с обычаем североамериканских индейцев, называемым «потлач». Во время потлача вождь намерено раздаривал соседним племенам имущество своего племени с целью показать его богатство и могущество. Правда, зачастую за потлачем следовало полное разорение проведшего его племени, что говорит о том, что эти акты дарения не были взвешенными.

Примером дара, лишенного целенаправленности, можно считать приглашение угоститься. Человек, высказывающий такое приглашение, действительно хочет, чтобы с ним разделили трапезу. Он делает это взвешено, так как считает, что такое приглашение уместно, и он не будет испытывать невыносимый голод, если к его трапезе присоединяться. Более общей формулой для дарения без целеполагания служит фраза «отдам просто так». В рус- 
ском языке понятие «дар» содержится в двух выражениях: «наделить даром, подарить» и «отдать даром, отдать просто так». Однако представляется вполне ясным, что смыслы этих фраз различны. Родители ребенка могут разместить на соответствующих интернет-форумах объявление, согласно которому готовы отдать просто так детскую одежду, из которой ребенок вырос. При этом у родителей есть понимание, что их ребенку не нужны эти вещи, есть желание поделиться ими, но нет цели спасти от холода или дополнить гардероб какого-то конкретного ребенка. Действие «отдам просто так» находится на одной из линий, определяющих границу практик благотворительности. Направление денег в благотворительный фонд отличается от объявления «отдам просто так» прежде всего тем, что первое действие обладает целью, второе, как правило, нет. Жертвователям фонда небезразлично, будут ли направлены их деньги на помощь той категории нуждающихся, для которой был объявлен сбор средств. Родителей, отдающих просто так детские вещи, обычно не волнует, как часто будут чужие дети носить отданные вещи и будут ли их носить вообще. И даже если родители, отдавшие вещи, узнают, что одежда потерялась или пришла в негодное состояние при перевозке, то вряд ли они подвергнут моральному осуждению виновников такого развития событий.

При этом из этического смысла благотворительности и практики «отдам просто так» не исчезают и такие факторы, как узость или широта категории потенциальных выгодоприобретателей, и возможность использования направляемых им ресурсов. Однако эти факторы не служат признаком, который позволяет отличить благотворительность как пример дарения и практику «отдам просто так». Отличительной же их чертой служит целенаправленность действия.

\section{ПОСМЕРТНОЕ ДОНОРСТВО:}

\section{НАМЕРЕННОЕ И ОБДУМАННОЕ, НО НЕ «ЦЕЛЕНАПРАВЛЕННОЕ»}

Именно в силу отсутствия целеполагания согласие стать посмертным донором больше схоже с практиками «отдам просто так», чем с благотворительностью. Разрешение использовать тело после смерти не подразумевает, что дающий его человек осуществляет целеполагание, т. е. «держит в уме» класс возможных ситуаций, в которых видны эффекты использования донорских органов. При этом решение стать посмертным донором может иметь правовой и этический смысл только при условии намеренности и взвешенности этого выбора. Высказывание о согласии стать донором может стать руководством к действиям трансплантологической бригады после смерти субъекта только если: 
- высказывание сопровождалось намерением сделать именно этот выбор (т. е. человек был дееспособен и не находился под давлением);

- высказыванию предшествовал процесс обдумывания этого решения ${ }^{2}$.

Представление же о том, что готовность стать донором органов после смерти сопровождается целеполаганием, не только меняет этический смысл этого действия, но и ведет к искаженному распределению ответственности за исполнение этого решения. Добровольность и этическая значимость решения о донорстве исчерпывается тем, что его сопровождало (намерение, желание сделать только этот выбор) и предшествовало ему (взвешивание этого решения). Целеполагание - выработка представлений о будущих результатах использования донорских органов - представляется ненужным дополнением. Оно неверно характеризует сам акт принятия решений и вместе с тем налагает неадекватные обязательства по реализации несуществующей цели.

С другой стороны, формула «тело как дар» применяется прежде всего для социального подталкивания (nudging) к выбору в пользу согласия стать посмертным донором. Вероятно, во многих случаях она работает эффективно. Однако взвинчивание моральной цены согласия стать донором чревато ростом социальных рисков развития трансплантологической помощи.

Как было отмечено в начале статьи, в рамках информационной компании в поддержку донорства органов сопоставляются жизненные истории доноров и реципиентов. Тем самым формулируется цель посмертного донорства: помочь группе людей, испытывающих определенные проблемы со здоровьем. Можно допустить, что манипуляция даже с релевантными данными о соотношении числа смертей потенциальных доноров и числа трансплантаций, о качестве жизни реципиентов после операций способны во многом девальвировать сформулированную такими средствами цель. В результате эффект информационной компании будет нивелирован, а система трансплантологической помощи может понести репутационные издержки.

Вне зависимости от типа правовой регуляции донорства органов выглядит целесообразным в рамках информационных кампаний обращаться не столько к целеполаганию готовности стать донором, сколько к взвешиванию этого решения. Представления о медицинских и правовых практиках, лежащих в основе органного донорства, позволят человеку проще взвесить свой выбор. Выбор отдать «просто так» и распорядиться отдельными органами

\footnotetext{
2 Сомнения во взвешенности согласия стать донором органов, зафиксированным в водительских правах в Новой Зеландии, часто служит причиной того, что эксплантация органов не осуществляется (Wilkinson M., Wilkinson S., 2016). Т. е. предполагается, что при получении водительского удостоверения субъект мог не иметь достаточного времени, чтобы дать взвешенное согласие.
} 
после смерти выглядит более простым, чем решение преподносить свое тело как дар.

\section{ЗАКЛЮЧЕНИЕ. РОССИЙСКИЙ РЕГИОНАЛЬНЫЙ КОНТЕКСТ}

Можно рассмотреть приведенную в двух предыдущих разделах критику позиции Кристофера Мичетти и ее предпосылки с более общих философских позиций. Это может производиться в ракурсе, обозначенном теорией рациональности и рационального действия, предложенной Джоном Серлем, продолжателем идей Джона Остина (Searle, 2003). Рассматривая основания человеческих действий, в том числе альтруистических, Серль отмечает, что нельзя смешивать способы целеполагания при формировании убеждений и при планировании поступка. Целью формирования убеждения является истина, зачастую доступная для интерсубъективной проверки. Для намерения действовать то место, которое занимает истина для убеждения, остается вакантным. Цель поступка всегда представлена «интенциональным содержанием отдельного субъекта», ее нельзя универсализировать, считать тождественной при совершении одинаковых действий, выражении желания действовать сходным образом. Но именно в такой универсалистской этике и эпистемологии и становится возможным воспроизводство практики дарения (частей) тела. Именно с подобных универсалистских позиций обозначает свою позицию Мичетти.

Быть может, существуют люди, воспринимающие возможность посмертного донорства как целенаправленный дар. Но такая точка зрения не является всеобщей, не служит она и логически необходимым следствием согласия с такой посмертной судьбой тела. Задача выяснить «интенциональные содержания» каждого потенциального донора видится трудновыполнимой и лишенной практической необходимости.

Примеряя высказанную выше критику к российским региональным контекстам органного донорства, можно заключить, что усиленное воспроизводство эпистемических и этических условий восприятия тела как дара может быть не только излишним, но и вредным. Во-первых, в России действует презумпция согласия на посмертное донорство, а инфраструктура «дарения частей тела» возникла в ином правовом, этическом и политическом контексте. Ее воспроизводство через простое копирование локальных коммуникативных полей, вроде австралийской «Книги жизни», способно вступить в противоречие с условиями функционирования opt-out системы. Во-вторых, работа этой системы требует гораздо меньших усилий по созданию культурной инфраструктуры, она способна осуществляться на гораздо более скромных и легко воспроизводимых основаниях. Достаточно, чтобы согласие (не- 
выраженное несогласие) с возможностью посмертного донорства было намеренным и обдуманным. При этом нет необходимости формировать или выяснять целеполагание решения о согласии или отказе от посмертного донорства.

\section{СПИСОК ЛИТЕРАТУРЫ}

Ahmad, M. U. et al. (2019) A systematic review of opt-out versus opt-in consent on deceased organ donation and transplantation (2006-2016) / M. U. Ahmad, A. Hanna, A.-Z. Mohamed, A. Schlindwein, C. Pley, I. Bahner, R. Mhaskar, G. J. Pettigrew, T. Jarmi // World Journal of Surgery. Vol. 43. Issue 12. P. 31613171. DOI: $10.1007 / \mathrm{s} 00268-019-05118-4$

Austin, J. L. (1966) Three ways of spilling ink // The Philosophical Review. Vol. 75. No. 4. P. 427-440. DOI: $\underline{10.2307 / 2183222}$

Donation stories (s.d.) [Электронный pecypc] // DonateLife: Organ and Tissue Authority. URL: https://donatelife.gov.au/donation-stories [архивировано в WaybackMachine] (дата обращения: 10.10.2019).

Michetti, C. P. (2019) Patient-centered practices in organ donation // American Journal of Transplantation. No. 00. October 12. P. 1-5. DOI: 10.1111/ajt. 15649

Murphy, M. (2017) The economization of life. Durham ; L. : Duke University Press. ix, 220 p.

Searle, J. R. (2003) Rationality in action (Jean Nicod lectures). Cambridge, MA ; L. : The MIT Press. xvi, 303 p.

Wilkinson, M., Wilkinson, S. (2016) The donation of human organs // The Stanford encyclopedia of philosophy (Winter 2016 Edition) / ed. by E. N. Zalta. October 3. URL: https://plato.stanford.edu/archives/win2016/entries/organ-donation [архивировано в WaybackMachine] (дата обращения: 10.10.2019).

Дата поступления: 13.10.2019 2.

\section{REFERENCES}

Ahmad, M. U. et al. (2019) A systematic review of opt-out versus opt-in consent on deceased organ donation and transplantation (2006-2016) / M. U. Ahmad, A. Hanna, A.-Z. Mohamed, A. Schlindwein, C. Pley, I. Bahner, R. Mhaskar, G. J. Pettigrew and T. Jarmi. World Journal of Surgery, vol. 43, issue 12, pp. 3161-3171. DOI: 10.1007/s00268-019-05118-4

Austin, J. L. (1966) Three ways of spilling ink. The Philosophical Review, vol. 75, no. 4, pp. 427-440. DOI: $\underline{10.2307 / 2183222}$ 
Donation stories (s.d.) DonateLife: Organ and Tissue Authority [online] Available at: https://donatelife.gov.au/donation-stories [archived in WaybackMachine] (дата обращения: 10.10.2019).

Michetti, C. P. (2019) Patient-centered practices in organ donation. American Journal of Transplantation, no. 00, October 12, pp. 1-5. DOI: 10.1111/ajt. 15649

Murphy, M. (2017) The economization of life. Durham ; London : Duke University Press. ix, $220 \mathrm{p}$.

Searle, J. R. (2003) Rationality in action (Jean Nicod lectures). Cambridge, MA ; London : The MIT Press. xvi, 303 p.

Wilkinson, M. and Wilkinson, S. (2016) The donation of human organs. The Stanford encyclopedia of philosophy (Winter 2016 Edition) / ed. by E. N. Zalta. October 3. [online] Available at: https://plato.stanford.edu/archives/win2016/ entries/organ-donation [archived in WaybackMachine] (дата обращения: 10.10. 2019).

Submission date: 13.10 .2019$.

Шевченко Сергей Юрьевич - кандидат философских наук, научный сотрудник сектора гуманитарных экспертиз и биоэтики Института философии Российской академии наук; преподаватель кафедры биоэтики Российского национального исследовательского медицинского университета имени Н. И. Пирогова. Адрес: 109240, г. Москва, ул. Гончарная, д. 12, стр. 1. Тел.: +7 (495) 697-90-67. Эл. адрес: simurg87@ list.ru

Shevchenko Sergei Yurievich, Candidate of Philosophy, Researcher, Department of Humanitarian Expertise and Bioethics, Institute of Philosophy, Russian Academy of Sciences; Lecturer, Department of Bioethics, Pirogov Russian National Research Medical University. Postal address: Bldg. 1, 12 Goncharnaya St., 109240 Moscow, Russian Federation. Tel.: +7 (495) 697-90-67. E-mail: simurg87@list.ru

ORCID: 0000-0002-7935-3444

Researcher ID: F-5320-2018

Scopus Author ID: 57192993265

SPIN-код РИНЦ: 2783-6006 
Для цитирования:

Шевченко С. Ю. Локальные и региональные контексты органного донорства: этика и эпистемология тела как дара [Электронный ресурс] // Горизонты гуманитарного знания. 2019. № 4. C. 35-47. URL: http://journals.mosgu. ru/ggz/article/view/1059 (дата обращения: дд.мм.гггг). DOI: 10.17805/ggz.2019. $\underline{4.3}$ 